\title{
The Study on Dealing with Emergency Incidents and Government Crisis Management-A case of Yunnan travel mess survey
}

\author{
Liu Yun ${ }^{1}$ Zhu Ying ${ }^{2}$ Si Jinxia ${ }^{3}$ \\ ${ }^{1,2,3}$ School of Tourism, Yunnan University of Economics and Finance , Kunming, P.R.China, \\ 650221 \\ (E-mail:lydepartment@126.com, zhuying19880226@163.com,841057205@qq.com)
}

\begin{abstract}
Because of the vulnerability and sensitivity of tourism industry, it is easily influenced by environment significantly, which makes itself fall into crisis deeply. This article applies the $4 \mathrm{R}$ theory of crisis management, and then summaries the effective measures of relevant administrative departments of Yunnan tourism when facing to the emergency incidents based on reviewing the event of "Yunnan travel mess survey", Then, the article points out that Yunnan tourism administrative department must build a tourism crisis management mechanism in order to avoid similar events and puts forward corresponding suggestions for the tourism crisis management mechanism as well.
\end{abstract}

Keywords: Yunnan travel mess survey; emergency incidents; the $4 \mathrm{R}$ theory; the tourism crisis management mechanism

\section{Introduction}

In July 2010, it was, for the first time, clearly claimed that tourism was going to be cultivated into a "Strategic Pillar Industry" of national economy in the regulation of "Views of the State Council on Accelerating the Development of Tourism". Therefore, the status of tourism has become increasingly important in the national economy. The tourism industry is a highly sensitive and relevant industry, and the comprehensiveness and dependency of its development is rather easy to be influenced by unexpected incidents in the fields of geography, politics, economy, culture, ecology, environment, and etc. Further, the phenomenon of tourism crisis caused by sudden events is more and more striking, thus exerting an enormous influence on world economy. For instance, the SARS event happened in 2003, and the Thailand tensions and Japanese earthquake \& tsunami occurred in 2011. In this case, there is no doubt that the study of tourism crisis becomes an important issue.

Foreign scholars' researches on the tourism crisis are earlier than China's. Scholars divided the events that may create danger to tourism into the following aspects: terrorism, war, crime and economic crisis to research tourism crisis management respectively. Richter firstly researched the crisis brought by terrorism on the tourism[1]. Blake A.\&Sinclari T.M. analyzed the tourism crisis caused by the events of 11.September in the United States and effects caused by crisis reaction, then by establishing the computable general equilibrium model, they suggested that the most effective means of tourism crisis management were the specific target compensation and to reduce the tax[2]. In addition, Raab \& Schwer researched the tourism crisis caused by economic crisis by investigating both long-term and short-term effects of Asian financial crisison the Las Vegas gaming revenue[3]. The research of tourism crisis of domestic scholars started in 2003 after the event of SARS, focusing on both macro and micro aspects of tourism industry. Shen Hejiang \& Chen Shurong (2006) mainly researched the macro aspect of tourism industry and made a contribution to putting forward the necessity of taking crisis management on tourism on the basis of introducing the concept and model of tourism 
crisis management. Besides, Li Feng (2009) took Wenchuan earthquake as the example to suggest that government, tourism enterprises and tourism industry association were the main body of tourism crisis management and they had different points of emphasis at different stages of tourism crisis management. On the other hand, Wang Dingling (2007), Chen Tiantian, Wang Jianxi (2009), Zhu Xiaomei, Zhang Yajing (2008) and other domestic scholars respectively researched tourism crisis management in view of the specific tourism industry from the perspective of hotel companies, travel agencies, tourism attractions[4].

\section{The review of "Yunnan travel mess survey"}

On January 8, 2012, "Society and Law" program on CNTV ( Central Network Television Visual) aired an report called "Yunnan travel mess survey", teasingly reported that Yunnan broken through the traditional version of "Yunnan eighteen strange", meaning that there occurred the phenomenon of the "nineteenth strange", which was expressed through the 6 elements of tourism: eating---eight dishes in travelling, accommodation---turning the standard room into dormitory making tourists questioned the star standards, transportation---drivers took part-time jobs putting tourists' security into danger, travelling---glancing over various scenic spots hurriedly among mountains and rivers, shopping---tour guides becoming shopping guides and shopping was the most important part through the whole travel, entertaining---tourists sharing and entertaining at their own expenses[5]. After this report, "Yunnan tourism, complainants, chaos" became the key words in a flash, lashing against the gold-lettered sign board of "colorful Yunnan, paradise of tourism" with multi-frequency and high click-through; therefore, Yunnan tourism stepped into "deep crisis" instantly.

\section{The 4R Theory of Crisis Management}

The 4R Theory of Crisis Management, which is composed by 4 stages- Reduction, Readiness, Response, Recovery, was first put forward in the book named Crisis Management by the U.S. crisis management expert Robert Heath[6]. As is shown in the figure:

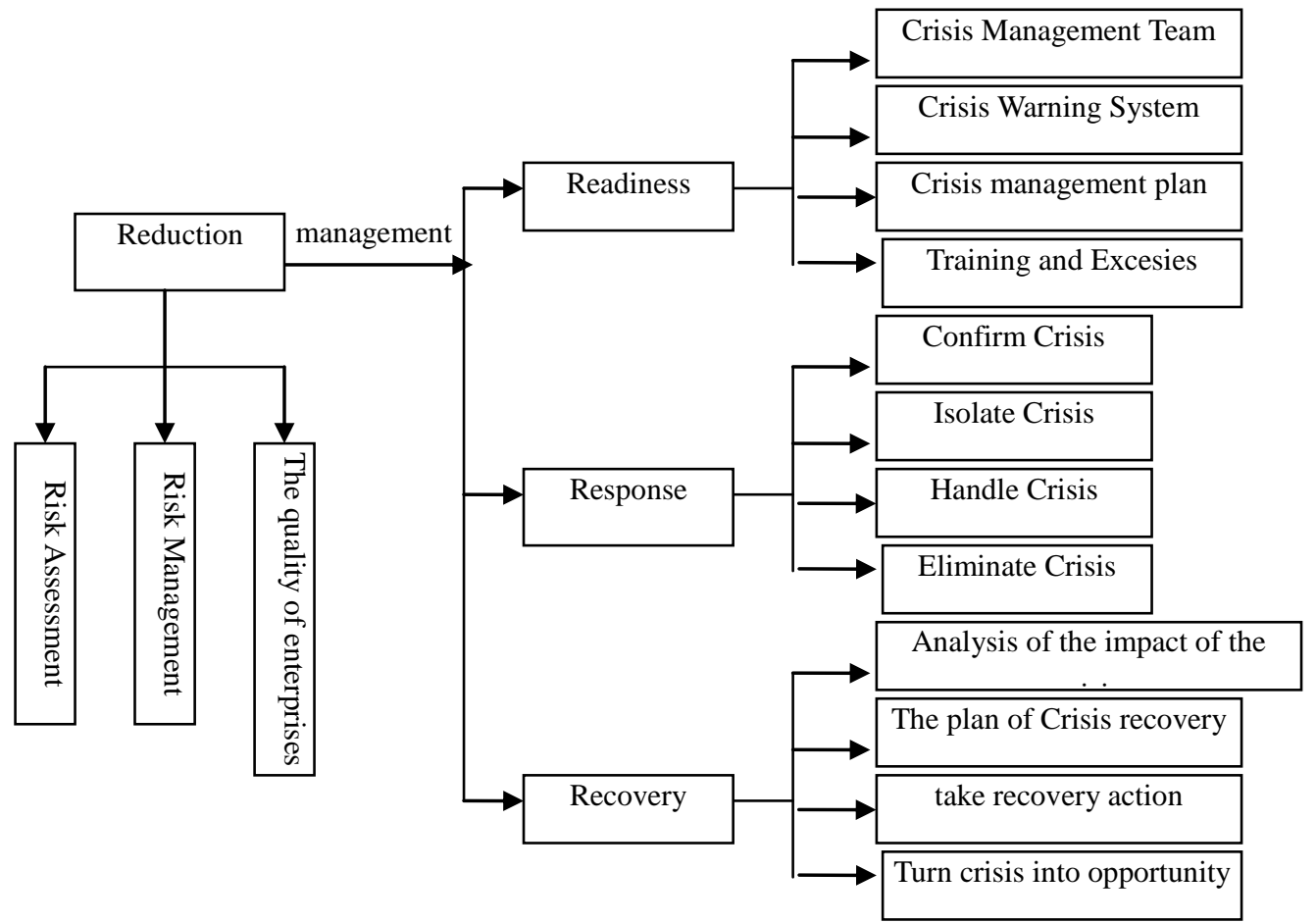

Fig.1: 4R-model of Crisis Management

Crisis reduction management is the core of crisis management, which impenetrate the entire process of crisis management. By building this into the environment, 
structure, system and staff, the Reduction will reduce the risk, avoid wasting time and lower the probability of poor resource management. It is also capable of greatly reducing the incidence and the impact of crisis.

Prepare management is mainly used for crisis prevention. Enterprises can select various experts to form a crisis management team, develop a crisis management plan and use the risk assessment method of reducing management to determine which early warning systems might fail in order to promptly amend or strengthen them and to establish a complete and effective crisis early warning system.

The enterprises on the level of reaction force firstly have to solve the problem of how to win more time to deal with the crisis, which is followed by how to obtain more comprehensive real information to get to know the root and incidence of the crisis in time and to provide an effective basis for the crack of crisis. Finally, the enterprises have to solve the problem of how can they reduce the minimum loss to eliminate the crisis after the crisis. In summary, the four steps in management strategies, which the enterprise used to cope with crises, are identifying crisis, crisis isolation, crisis dispose and elimination of crisis.

Restoring force is mainly reflected in setting about recovering and enhancing the subsequent image after the crisis happened and being controlled. It is also the summary phase after the crisis management, and provides experience and support for future crisis management.

\section{Application of $4 R$ in dealing with crises after emergencies of Yunnan Tourism Administrative Department}
After the "Survey of Yunnan travel chaos" being reported, Yunnan Tourism Administrative Department traced the cause to its root. The cause was mainly reflected in two aspects. One was the "zero and negative tour expense" of travel agency and the other was the salary of tour guide, which made the phenomenon of "Gambling group consumption" of Yunnan tour guides become very common. This sudden report of "Survey of Yunnan travel chaos" made

Yunnan Tourism Administrative Department face a series of crisis management issues such as facing the crisis, responding to the crisis, eliminating the crisis and so on. In view of the solutions of crisis management in emergencies taken by Yunnan Tourism Administrative Department, the analysis of Heath 4R model of crisis management by Robert Heath is as follows:

\subsection{Reduction}

As a matter of fact, irregularities which damage the image of Yunnan tourism has appeared in succession since 2004, such as "Kunming one day tour and One day in seven shops", "Shilin Sightseeing tour and Burning incense on the way" , "Driver turned into Tour Guide and Tour Guide turned into Shopping Guide of Dali \& Lijiang Tour" and so on. Some media sometimes also expose these irregularities. In view of this, Yunnan Tourism Administrative Department began to implement a series of measures to manage existing crisis and to monitor potential risk.

\subsubsection{Setting up and supporting the 16 major travel agencies}

Sixteen major travel agencies of Yunnan province which are produced within the industry bidding mode officially began to enjoy policy support since August, 1st, 2010. Yunnan province hopes to determine the tourist package standard province-wide by cultivating leading enterprise and create a fair and stable tourism market environment, while maintaining the interests of travel agency.

\subsubsection{Playing the role of the media power positively}

With the help of the media power, Yunnan province carried out a thorough investigation to conduct an in-depth investigation on Yunnan's tourism enterprises and tour groups. Once the operation of unhealthy fee is proved to be true, they will be severely punished according to the law. At the same time, it evaluates the grading standards of travel agencies in hope of constantly improving travel agency's service quality. 


\subsubsection{Uniting the media to expose tourist cost information}

Yunnan province vigorously unites with media of high credibility, publishing guiding price information of tourist cost, which allows tourists to get tourism information timely and makes their tourism consumption behavior more rational while making the competition in tourism market more transparent.

\subsubsection{Strengthening the force of punishment}

Based on the "Price Law" ,"Regulations on Travel Agencies", "Travel Agency Implementation of the Regulations", "Yunnan Travel Regulations" and other relevant laws and regulations, Yunnan Province devotes major efforts to investigate and deal with the phenomenon of "zero and negative tour expense" of travel agency. Once it is found, the tourism authorities will take very severe punishment measures, such as revocation of license and heavy fine in order to maintain the operation order of the tourism market.

\subsection{The strength of preparation}

Facing irrational phenomenon in Yunnan tourism, the Yunnan Tourism Administration Department, on the one hand, strengthened the effort in supervisory control and management, and on the other hand enhanced preventive work. With regard to the existence of the travel chaos in Yunnan, Yunnan adhered to the comprehensive improvement pattern of the "government dominating, sectors making joint effort, enterprises being main body and society participating". By vigorously establishing and perfecting the working mechanism of leadership of government and the division of labor and cooperation between sectors. The leading group of reform and development of Yunnan tourism industry took overall responsibility for the comprehensive improvement of the tourism market all over the province, other relevant departments performed their own functions and unified with coordination, and the states and municipalities established the working mechanism of comprehensive improvement in line with regional tourism, thus forming a province-wide management network for tourism crisis.

\subsection{The strength of reaction}

\subsubsection{Immediately convoking meetings to discuss the way of settlement}

Shortly after the incident of "the survey of Yunnan travel chaos", the leading group of reform and development of Yunnan tourism industry held an emergent mobilization meeting for the comprehensive improvement of tourism market of the province and positively responded to the questions on Yunnan tourism from different sectors of the community. During the meeting, 2012 was decided to be the year of comprehensive improvement of tourism market in Yunnan, and the solution to the problem of zero and negative tour expense and tour guides' salary was discussed, and at the same time a monographic study of "zero and negative tour expense" and the commission proportion of travel was carried out[7]. In face of the sudden crisis, Yunnan Tourism Administration Departments established the crisis management plan in the first time with great initiative and active communication, taking the first step to successfully deal with this tourism crisis.

\subsubsection{Using media to respond positively}

When "Yunnan travel chaos" was pointed out, instead of evading the problem or shirking responsibility, the Tourism Administrative Department of Yunnan Province but actively took advantage of the media to respond to the unreasonable phenomenon in tourism referred in the report. Relevant departments in charge of the Yunnan Provincial Tourism Bureau have been interviewed several times to explain relevant issues, and have publicly put forward solutions to the travel chaos and friendly hints to Yunnan tourist as well. Yunnan Tourism Administration department's manner of actively admitting its mistakes and positively addressing them, to some extent, won the understanding from the media, tourists and people of all walks of life and laid the foundation for the successful resolution to tourism crisis.

\subsubsection{Strengthening the force of putting law into practice}

With variety of ways, such as the joint law enforcement, setting up to check and 
market inspection etc., the supervision of irrational operating behavior in tourism within the province will be strengthened and the dealings of illegal typical cases will be publicized. The construction of the platform for a dynamic regulation of Yunnan tourism market will be sped up, and more scientific methods to improve the effectiveness of law enforcement will be employed. Electronized management will be tried out in travel agencies, tourist groups. Moreover, tourism elements and the quality of tourism service will be included in the informationized dynamic regulation to supervise the orbit of tourist groups.

\subsection{Restoring force}

\subsubsection{Promoting the standardized operation of tourism industry}

Yunnan tourism administrative departments continues to adopt the local standard measures referring travel agents, tour guides, shopping and travel transportation put out in 2009 to grade tourism business units. Meanwhile, by establishing research topics and defining the measurement of "zero and negative tour expense" and the proportion of tourism commission, the establishment, perfection and implementation of the commission mechanism of "public to public" and the tour guide payment mechanism will be further promoted.

\subsubsection{Positively elaborating the affection of industry association}

Yunnan Province not only relied on government forces, but also vigorously led the guilds to solve the problem of Yunnan travel chaos jointly by perfecting guild regulations, innovating working methods and setting up a credit system of this industry. Firstly, tourism guilds took the commonly agreed rules and regulations within the industry as the standard to punish members conducting illegal operations; Secondly, guilds should also supervise and resist irrational tourism behaviour within other industries, jointly protecting the healthy development of tourism.

\subsubsection{Consummating the supervision mechanism}

The supervision mechanism in tourism should be actively perfected and the interactive mechanism of management and supervision should tentatively established, which means that tourism administration departments of different levels should manage with joint effort and supervise on each other with collinear supervision departments. And at the same time by bringing into full play public opinions and supervision of the media, tourists and people of all walks of life, all kinds of tourism enterprises and practitioners who disturb the order of Yunnan tourism market will be publicized, thus more effectively and comprehensively eradicating behaviours resulting to the Yunnan tourism chaos.

\section{Countermeasures of Building Yunnan Tourism Crisis Management System}

\subsection{Activating the contingency plan mechanism}

The foundation and core of the tourism crisis management lie in prevention. Only when we are fully prepared in advance can we make timely and correct decisions in times of crisis. Therefore, in order to construct the Yunnan tourism crisis management mechanism, we should first enhance the building of contingency plan mechanism. The contingency plan mechanism mainly refers to the prediction and monitoring of tourism crisis. Yunnan tourism administrative departments should monitor, collect and analyze the information of the tourism market at any time in order to detect the indication of the crisis and predict crisis situations; for example, the number of tourists decreased and tourist complaints increased[8].

However, because of the sensitivity and vulnerability of tourism industry itself, the practical and effective tourism crisis contingency plan can't only rely on the tourism sector, but also requires linkage and cooperation with many other departments such as the Ministry of Foreign Affairs, Ministry of Public Security, Ministry of Transportation, Bureau of Meteorology and so on. Therefore, in the 
construction of the mechanism of Yunnan Tourism crisis management contingency plan, we should follow the linkage and cooperation model of the tourism administrative departments taking the lead, other relevant departments being assistant, and tourism enterprises being the main body, making efforts to construct an overall platform for information collection and monitoring, thus forming an integrated and effective contingency plan mechanism.

\subsection{Establishing the rapid response mechanism}

The construction of Yunnan tourism crisis management mechanism also requires the establishment of a rapid response mechanism, which can conduct effective and appropriate crisis management when the crisis arrives. This requires the formulation of various crisis plans, the organization of the tourism crisis response group or tourism crisis special handling institutions, and the employment of high-quality professional personnel to avoid the happening of crisis effectively or minimize its loss after the crisis happening as much as possible[9].

At the same time, tourism crisis management simulation trainings, including the learning of crisis management knowledge, crisis handling techniques and psychological training, should be done regularly to effectively improve rapid reaction capability of government towards the tourism crisis management and check the feasibility of the already-drafted crisis contingency plan.

\subsection{Strengthening the crisis management mechanism}

In general, the generation of any tourism crisis is abrupt and urgent. So despite there existed a contingency plan mechanism as prior regulation of the crisis, because the unpredictability exists in crisis, all preventive measures are not foolproof[9]. This requires that government sectors should act according to changing circumstances in face of crisis, so that to strengthen the real-time processing ability of the government towards the tourism crisis becomes crucial. When a crisis occurs, we should immediately identify the root-cause of the crisis at first and calm tourists' emotion down timely in a positive and honest way. Secondly, we should deal with it calmly and give top priority to the interests of tourists, formulating reasonable management alternatives and giving reasonable compensation to as well as achieving understanding from travelers affected by the crisis. At last, we should take effective measures to isolate the crisis and stop the situation from further spreading, and deal with the crisis according to its cause.

\subsection{Improving the information release system}

The communication of information is very important after the tourism crisis. Good communication based on honesty and transparency is the key to successfully dealing with the tourism crisis. Therefore, the construction of the Yunnan Tourism crisis management mechanism is also inseparable from the information release system. Yunnan tourism administrative departments should make use of many forms of television, radio, newspapers, Internet and so on to construct a unified and integrated tourism crisis management information disclosure system, adhering to the principle of honesty and transparency to keep in touch with tourists and the media. When a crisis occurs, Yunnan tourism administrative departments should publish accurate and reliable information of the crisis rapidly and endeavor to gain their understanding and support to maintain the confidence of tourists and protect regional tourism image of Yunnan.

\subsection{Cracking crisis public relations}

The generation of tourism crisis will bring negative impact on tourist destination inevitably. So after the tourism crisis is successfully resolved, Yunnan tourism administration departments should take effective public action to re-establish the image of tourism in Yunnan. Yunnan tourism administration departments strengthened collaboration with the various news media, tourist resorts and travelers both at home and abroad, taking the strategy of "inviting" and "going out"。On the one hand, the government could conduct emotional communication, striving for more support and positive publicity, and give public notice to tourist source the anti-crisis measures and the restore tourism 
measures through the media to achieve the purpose of reshaping the tourism image and reconstructing tourists' sense of trust in Yunnan tourism. On the other hand, the government should strengthen the tourism marketing efforts, especially for the mainstream source markets, and increase efforts in tourism promotion, introducing new tourism products and implementing preferential policies for tourism, such as introducing new tourism products and new lines through the combination of packaging, and providing a more favorable price and better service. Meanwhile, Yunnan tourism administrative departments can also invite domestic and overseas media reporters to return to the destination to show them the remediation results after the crisis, ensuring full access and experience between the media and tourist destination to achieve the purpose of tourism promotion.

\section{Conclusion}

The vulnerability and sensitivity of the tourism industry decides that it is bound to be greatly hit in face of unexpected events. If we don't take preventive measures, it is likely to cause unrestrained harm to the tourism industry once the crisis happens. Therefore, the existence of the Yunnan Tourism Crisis Management is necessary and building a tourism crisis management mechanism can solve the disaster brought by a number of unexpected events in tourism through prevention, monitoring, treatment and recovery comprehensively and effectively, minimizing the economic loss of tourism and the damage in the reputation of tourist destination caused by tourism crises, effectively promoting the rapid recovery of the tourism industry after the crisis, thus maintaining the healthy and stable development of tourism.

\section{References}

[1] Richter, L.K. (1983). Tourism politics and political science: A case of not so benign neglect. Annals of Tourism Research,10: 313-335.

[2] Blake A. \& Sinclair T.M. (2002). Tourism Crisis Management: response to September 11th. Christel DeHaa Tourism and Travel
Research Institute, Nottingham University Business School.

[3] Raab,C. \& Schwer, R.K. (2003). The short and long-term impact of Asian financial crisis on Las Vegas Strip baccarat revenues International. Journal of Hospitality Management. 22(1):37-45.

[4] Chai Shousheng, Cao YanMei, Long Chunfeng. (2011). Domestic tourism crisis management research review. Qingdao hotel management professional technology institute, (7):6-10 (In Chinese)

[5] Han Yi. (2012). Yunnan tourism crisis and butterfly change. The spring city evening news, (2) (In Chinese)

[6] Robert heath. (2001). The crisis management. Wang Cheng et al. Beijing: citic publishing house. (In Chinese)

[7] Yu Fan. The speech in the mobilization on comprehensive of the province's tourism market. (In Chinese)

[8] Yuan Ligong. (2005). Constructing tourism enterprise crisis management model. Market BBS,(9):115-117 (In Chinese)

[9] Yan Qingmin, Xu Silong. (2011). Small and medium-sized travel enterprise crisis response research. China business, (11):140-141（In Chinese） 